Article

\title{
Can Satellite Precipitation Products Estimate Probable Maximum Precipitation: A Comparative Investigation with Gauge Data in the Dadu River Basin
}

\author{
Yuan Yang ${ }^{1}$ (D), Guoqiang Tang ${ }^{1}$, Xiaohui Lei ${ }^{2}$, Yang Hong ${ }^{1,3, *}$ and Na Yang ${ }^{3,4}$ \\ 1 State Key Laboratory of Hydrosciene and Engineering, Department of Hydraulic Engineering, Tsinghua \\ University, Beijing 100084, China; yangyuan15@mails.tsinghua.edu.cn (Y.Y.); 15201514761@163.com (G.T.) \\ 2 State Key Laboratory of Simulation and Regulation of Water Cycle in River Basin, Institute of Water \\ Resources and Hydropower Research, Beijing 100038, China; Lxh@iwhr.com \\ 3 Department of Civil engineering and Environmental Science, University of Oklahoma, \\ Norman, OK 73019, USA; ynnuist@hotmail.com \\ 4 Department of Hydrology and Water Resources, Nanjing University of Information Science \& Technology, \\ Nanjing 210044, China \\ * Correspondence: hongyang@tsinghua.edu.cn; Tel.: +86-10-62787394
}

Received: 30 July 2017; Accepted: 23 December 2017; Published: 27 December 2017

\begin{abstract}
Probable Maximum Precipitation (PMP) is an essential prerequisite in designing dams, spillways, and reservoirs in order to minimize the risk of overtopping infrastructure collapse, especially under today's changing climate. This study investigates conventional PMP estimation approach by using both scarce in-situ observations and mainstream satellite precipitation products in the Dadu River basin, where plenty of reservoirs and dams are being built. The satellite data include Climate Prediction Center (CPC) MORPHing algorithm (CMORPH), Precipitation Estimation from Remotely Sensed Information using Artificial Neural Networks-Climate Data Record (PERSIANN-CDR), and Tropic Rainfall Measuring Mission (TRMM) Multi-satellite Precipitation Analysis (TMPA) 3B42V7. The evaluation of satellite products shows that CMORPH and 3B42V7 agree well with gauge-based dataset for the period of 1998-2013 at both the grid and basin scales, also capturing the extreme precipitation events, with high Correlation Coefficients (CC) in terms of 0.68 and 0.71 , respectively. Also, CMORPH and 3B42V7 show better performance for the magnitude and spatial distribution of 24-h PMP in such complex terrains. PERSIANN-CDR shows an overestimation in the upstream and an underestimation in the downstream. As among the first studies of satellite precipitation-based PMP estimation, this work sheds lights on the suitability of satellite precipitation in PMP estimation and could provide a reference for future extended spatially-distributed PMP estimation in vast ungauged regions.
\end{abstract}

Keywords: probable maximum precipitation (PMP); satellite precipitation; statistical method; the Dadu River basin

\section{Introduction}

Dams, reservoirs, and other water infrastructures play a significant role in human society [1-3]. These hydraulic infrastructures guarantee water availability [4] and help to regulate disasters (e.g., floods and droughts) [5]. However, it should also be noted that dams and reservoirs can lead to even more severe disasters once they collapse, which will cause huge calamities downstream [6]. Over the world, about one-third of all dam failures are induced by insufficient spillway capacities [7]. Therefore, attention should be paid to the design of dams, particularly the capability of spillways 
to accommodate large floods. Probable Maximum Flood (PMF) is regarded as the design criteria of spillways [8,9], which is calculated from Probable Maximum Precipitation (PMP) in many countries, such as the United States, Canada, China, India, and Australia [10]. Thus, accurate estimations of PMP are very helpful to minimize the risk of overtopping dam collapse.

PMP is defined as the theoretical maximum precipitation for a given duration under modern meteorological conditions [11], and it is mainly calculated by the meteorological method and statistical method. The statistical method only needs precipitation data, and thus it is especially useful when there is insufficient meteorological data to conduct the meteorological method [12]. The statistical method that was developed by Hershfield $[13,14]$ is widely used in different countries, such as India [15,16], Spain [17,18], Iran [19,20], Japan [21], and Malaysia [22,23]. Many studies show that the Hershfield method can provide comparable PMP estimates to those obtained by the elaborate meteorological method [24]. Therefore, the World Meteorological Organization (WMO) [11] has suggested this method for estimating PMP at stations with long periods of daily rainfall data.

Almost all statistical PMP estimation are traditionally based on gauge records, which has several not negligible limitations. A major shortcoming of the gauge-based approach is that PMP values can only be generated at specific points where rain gauges are located. Interpolation or area-reduction curves are necessary for adjusting the point values to areas of various sizes [11]. However, for interpolation, method choices and rain gauge locations would affect the spatial distribution of PMP a lot. For area-reduction curves, more meteorological data are needed to establish the relationship. Unfortunately, few meteorological observations are available in sparsely gauged or ungauged areas.

Recently, satellite provides unprecedented precipitation information with various temporal and spatial resolutions, which would bring new opportunities for PMP estimation, especially over regions with few rain gauges or weather radars. Satellite precipitation is continuous in time and space and will not suffer from the uncertainty brought by interpolation or area-reduction curves. However, to our knowledge, there are few studies using satellite precipitation to estimate PMP. Therefore, the objectives of this study are (1) to evaluate three mainstream satellite precipitation products against a gauged-based precipitation dataset in the Dadu River basin of China, where plenty of reservoirs and dams are being built; and, (2) to estimate PMP using satellite precipitation products based on the statistical method. Three methods are used to check the rationality of PMP, including the comparison with other study results, worldwide storm records, and the frequency analysis based Gumble distribution. This work is expected to promote the application of satellite precipitation in PMP estimation.

The remaining part of this paper is organized as follows. Sections $2-4$ introduce the study area, data, and methodology. Subsequently, the evaluation and comparison of satellite precipitation data and of the detailed PMP results are shown in Section 5. Constructive discussion is presented in Section 6. The concluding remarks are summarized in Section 7.

\section{Study Area}

The Dadu River is located between $99^{\circ} 42^{\prime} \mathrm{E}-103^{\circ} 48^{\prime} \mathrm{E}$ and $28^{\circ} 15^{\prime} \mathrm{N}-33^{\circ} 33^{\prime} \mathrm{N}$, with a drainage area of $7.74 \times 10^{4} \mathrm{~km}^{2}$ in Sichuan province of China (Figure 1). It is a tributary of the Min River and a sub-tributary of the Yangtze River. The Dadu River basin is surrounded by mountains, with an elevation higher than $3000 \mathrm{~m}$. A bealock sited in the midstream with an elevation of around $2000 \mathrm{~m}$, which provides the transportation channel of water vapor. The average annual precipitation ranges from 800 to $1000 \mathrm{~mm}$, among which 80\% precipitation occurs from May to October. Large rainstorms are often observed in the downstream, where floods frequently occur due to heavy precipitation and complex topography [25].

The full length of the Dadu River is $1062 \mathrm{~km}$, and its elevation drop is $4175 \mathrm{~m}$. Therefore, the basin has rich hydropower resources, which rank fifth in the 13 large hydropower bases in China. Hydropower resources in the Dadu River are theoretically about 33,680 MW, which accounts for 72.9\% of the Min River and 23.6\% of Sichuan Province [26]. According to the government's plan, 29 cascade 
hydropower stations will be constructed along the mainstream. Therefore, it is meaningful to perform a study on PMP estimation in this basin.
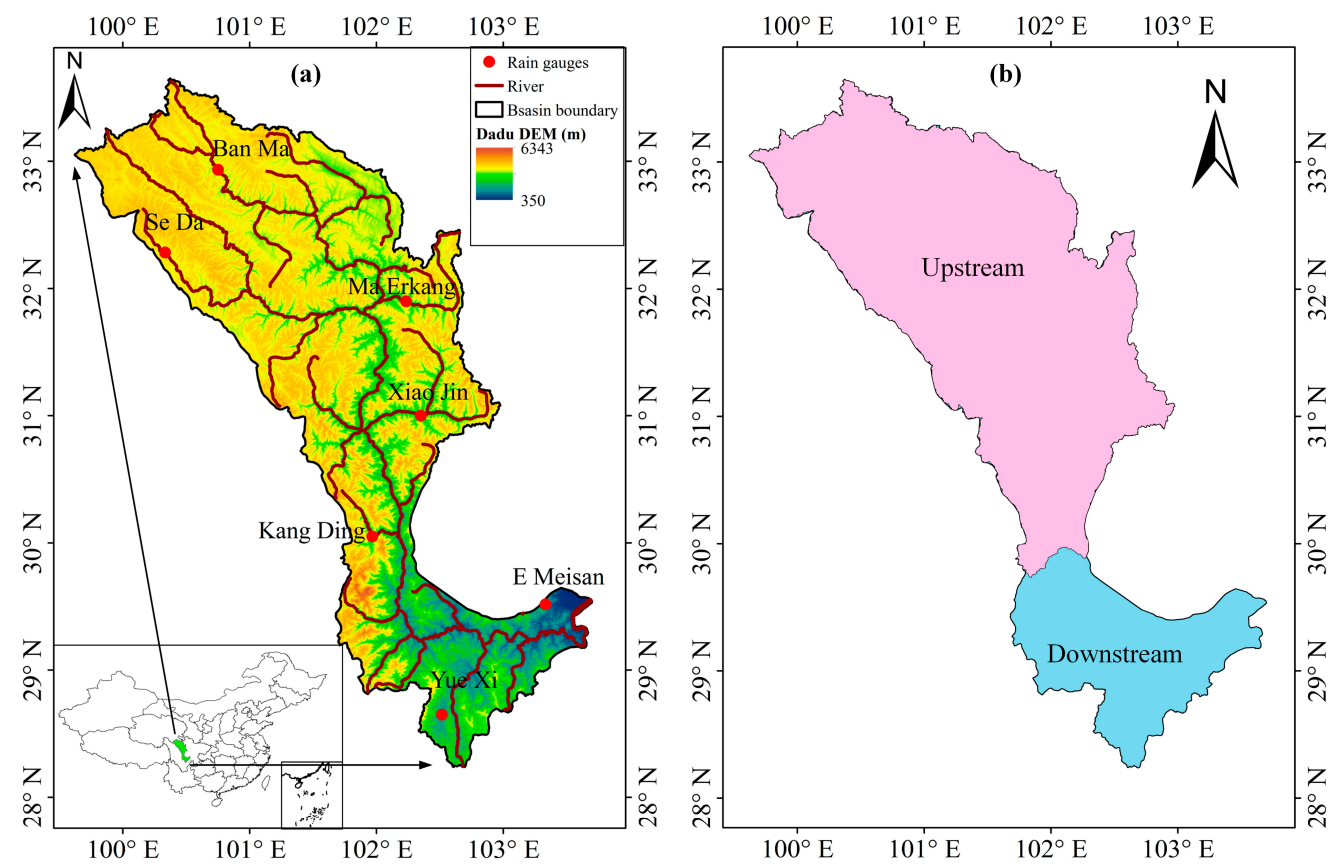

Figure 1. (a) Sketch map of the Dadu River basin and corresponding rain gauges; and, (b) Sketch map of sub-basins in the Dadu River basin.

\section{Datasets}

\subsection{Rain Gauge Precipitation Dataset}

The China Gauge-Based Daily Precipitation Analysis (CGDPA), with a $0.25^{\circ}$ and daily scale, was used as gauge dataset in this study. It is produced from more than 2400 gauge observations based on climatology-based optimal interpolation (OI) with topographic correction algorithm by the National Meteorological Information Center [27,28]. The data can be obtain from http://data.cma.cn/. CGDPA is a reliable precipitation dataset in Mainland China, particularly over the eastern and southern areas with higher density of stations. It has been systematically validated by Shen and Xiong [27] and found that the daily analysis has very good agreements with the observations over different regions of China. It has been shown that this dataset can accurately capture precipitation processes and has a definitive advantage in quantitative precipitation monitoring. It also has been successfully used in flood monitoring and climatological studies, even in the sparsely gauged regions, like the Tibetan Plateau and Xinjiang [29-38]. At present, CGDPA has been formally released as the official daily gridded precipitation product that is normally recommended as a readily available input to hydrological and meteorological applications over Mainland China [39]. The location of seven national rain gauges involved in CGDPA production in this basin is shown in Figure 1. It should be noted that the sparse gauge network could degrade the quality of CGDPA over the complex Dadu River basin and this potential effect is discussed in the following sections.

\subsection{Satellite Precipitation Dataset}

Three Level-3 satellite-based precipitation datasets were used in this study (Table 1), which included Climate Prediction Center (CPC) MORPHing technique (CMORPH) [40], Precipitation Estimation from Remotely Sensed Information using Artificial Neural Networks (PERSIANN)-Climate 
Data Record (PERSIANN-CDR) [41], and Tropical Rainfall Measuring Mission (TRMM) Multisatellite Precipitation Analysis (TMPA) research product 3B42V7 [42].

There are only 194 International Exchange Stations across the Mainland China [43] that are used to adjust TMPA and PERSIANN-CDR. The seven gauges that are used in this study are not included in the 194 gauge stations. Therefore, the evaluation and comparison do not suffer from the independence problem.

As among the early studies of PMP estimation based on satellite precipitation data, a spatial resolution of $0.25^{\circ}$ is fairly coarse and it might induce some uncertainties to capture extreme rainfall amounts, especially in mountainous regions. However, we primarily aimed at the feasibility of satellite precipitation in PMP estimation.

Table 1. General information of three satellite precipitation products in this study.

\begin{tabular}{|c|c|c|c|c|c|c|}
\hline Short Name & Full Name and Details & $\begin{array}{c}\text { Temporal } \\
\text { Resolution }\end{array}$ & $\begin{array}{c}\text { Spatial } \\
\text { Resolution }\end{array}$ & $\begin{array}{c}\text { Input } \\
\text { Data }\end{array}$ & $\begin{array}{c}\text { Retrieval } \\
\text { Algorithm }\end{array}$ & References \\
\hline CMORPH & $\begin{array}{l}\text { Climate Prediction Center } \\
\text { (CPC) MORPHing technique }\end{array}$ & Daily & 0.25 & 1998-2013 & $\begin{array}{l}\text { Morphing } \\
\text { technique }\end{array}$ & [40] \\
\hline PERSIANN-CDR & $\begin{array}{l}\text { Precipitation Estimation from } \\
\text { Remotely Sensed Information } \\
\text { using Artificial Neural } \\
\text { Networks (PERSIANN) } \\
\text { Climate Data Record (CDR) }\end{array}$ & Daily & 0.25 & 1983-2013 & $\begin{array}{l}\text { Adaptive artificial } \\
\text { neural network }\end{array}$ & [41] \\
\hline 3B42V7 & $\begin{array}{c}\text { Tropical Rainfall Measuring } \\
\text { Mission (TRMM) Multi-satellite } \\
\text { Precipitation Analysis (TMPA) } \\
\text { 3B42 Version } 7\end{array}$ & Daily & 0.25 & 1998-2013 & $\begin{array}{l}\text { GPCC monthly } \\
\text { gauge observation } \\
\text { to correct this bias } \\
\text { of 3B42RT }\end{array}$ & [42] \\
\hline
\end{tabular}

\section{Methodology}

\subsection{Hershfield Technique}

The essence of the Hershfield statistical method is storm transposition, but instead of transposing the specific rainfall amount of one storm, an abstract statistic $K_{m}$ is transposed. The procedure is based on the general frequency equation [44]:

$$
\begin{gathered}
X_{P M P}=\overline{X_{n}}+K_{m} S_{n}, \\
K_{m}=\frac{X_{m}-\overline{X_{n-1}}}{S_{n-1}},
\end{gathered}
$$

where $X_{P M P}$ is the PMP value for a station; $\overline{X_{n}}, S_{n}$ and $X_{m}$, are the mean value, standard deviation, and the highest value of a series of $n$ annual maxima, respectively. $\overline{X_{n-1}}$, and $S_{n-1}$ are the mean and standard deviation for this series excluding the highest value from the series. $K_{m}$ is the frequency factor at each grid, which can be calculated by Equation (2). In this study, the largest $K_{m}$ of all grids$K_{M}$ was chosen to be the $K_{m}$ of the whole basin.

During the estimation of PMP, we firstly employed the criteria proposed by Lin and Vogel [38] to check whether the survey period from 1998 to 2013 was enough for PMP estimation in the Dadu River basin. The minimum data size, $N_{m}$, is calculated by $N_{m}=T_{m}^{2}+2$, (where $T_{m}$ is the maximum deviation from the mean and computed by $\left.T_{m}=\left(X_{m}-\overline{X_{n}}\right) / S_{n}\right)$. All of the datasets, both satellite and gauge precipitation, satisfied the length check. However, this $N_{m}$ cannot necessarily guarantee a true estimate of PMP [45]. In this study, 3B42V7 and CMORPH data from 1998 (the year the two products are released) to 2013 were employed. In addition, we took full advantage of the long records of CGDPA (1961-2013) and PERSIANN-CDR (1983-2013) to explore the influence of data length on PMP estimation. Second, the sample mean $\overline{X_{n}}$ should be adjusted, because the frequency distribution of rainfall extremes is skewed to the right and the mean tends to increase with length of record. The adjusted mean can be computed by ${\overline{X_{n}}}^{\prime}=\left(1+3 * C_{v n} / \sqrt{n}\right) * \overline{X_{n}}$ (where ${\overline{X_{n}}}^{\prime}$ is the adjusted mean, $C_{v n}$ is the coefficient 
of variation) [38]. Third, precipitation data are usually recorded for fixed time intervals so that such data rarely yield the true maximum rainfall amounts for the indicated durations. Therefore, the annual maximum daily rainfall amounts for a single fixed time interval should be multiplied by 1.13 in order to yield values closely approximating those based on true maxima [11].

\subsection{Extreme-Value Type I (Gumbel) Distribution}

The extreme-value type I (Gumbel) distribution is a particular case of the generalized extreme value distribution [46], which is used to model the distribution of the maximum (or the minimum) of a number of samples of various distributions. It is useful in predicting the chance that an extreme earthquake, flood, or other natural disaster will occur $[47,48]$. A comprehensive study of various distributions was made by Hershfield and Kohlar [49], who found that Gumbel distribution is the most suitable one for annual maximum precipitation series. Therefore, the Gumbel distribution was chosen to fit to annual maximum precipitation series and various return period values were estimated. The detailed equation can be found in Leese [50].

\subsection{Statistical Metrics}

Several statistical metrics were used in this study, including the Correlation Coefficient (CC), Root-Mean-Square Error (RMSE), Mean Error (ME), Mean Absolute Error (MAE), Relative Bias (BIAS), Probability of Detection (POD), False Alarm Ratio (FAR), and Critical Success Index (CSI).

$\mathrm{CC}$ reflects the agreement between satellite precipitation and gauge-based observations. RMSE, $\mathrm{ME}, \mathrm{MAE}$, and BIAS are used to describe the error and bias of satellite precipitation. POD, FAR, and CSI are calculated to measure the consistency between satellite and gauge data [51,52]. The threshold of rain or no-rain events is defined as $0.1 \mathrm{~mm} / \mathrm{d}$ according to the rain gauges detection sensitivity. POD, FAR, and CSI range from 0 to 1 . The above metrics are calculated as:

$$
\begin{gathered}
\mathrm{CC}=\frac{\frac{1}{N} \sum_{n=1}^{N}\left(f_{n}-f^{\prime}\right)\left(r_{n}-r^{\prime}\right)}{S D_{f} S D_{r}}, \\
\mathrm{RMSE}=\sqrt{\frac{1}{N} \sum_{n=1}^{N}\left(r_{n}-f_{n}\right)^{2},} \\
\mathrm{ME}=\frac{1}{N} \sum_{n=1}^{N}\left(f_{n}-r_{n}\right), \\
\mathrm{MAE}=\frac{1}{N} \sum_{n=1}^{N}\left|r_{n}-f_{n}\right|, \\
\mathrm{BIAS}=\frac{\sum_{n=1}^{N}\left(f_{n}-r_{n}\right)}{\sum_{n}^{N} \times 1 r_{n}} \times 100 \%, \\
\mathrm{POD}=\frac{H}{H+M \prime} \\
\mathrm{FAR}=\frac{F}{H+F \prime} \\
\mathrm{CSI}=\frac{H}{H+M+F \prime}
\end{gathered}
$$

where $N$ is the number of samples; $f_{n}$ and $f^{\prime}$ stand for individual and averaged satellite rainfall estimates; and, $r_{n}$ and $r^{\prime}$ indicate individual and averaged gauge-based measurements. $S D_{f}$ and $S D_{r}$ represent standard deviations of satellite and gauge data. $H$ represents the observed rain by gauge, which is detected by satellite correctly, while $M$ is the observed rain not detected, and $F$ is not the observed rain, but detected falsely. 


\section{Results}

\subsection{Evaluation and Comparison of Precipitation}

To understand the impact of precipitation inputs on PMP estimation, the accuracy of the satellite precipitation was firstly evaluated against gauge observations. Figure 2 shows the spatial distribution of mean annual precipitation of CGDPA, CMORPH, PERSIANN-CDR, and 3B42V7, from 1998 to 2013 in the Dadu River basin. The precipitation amount of CGDPA, CMORPH, PERSIANN-CDR, and 3B42V7 ranged between 578 1646 mm, 408 1326 mm, 722 1180 mm, and 567 1351 mm, respectively. All of the products performed an upstream-to-downstream increasing trend. Low precipitation occurred in the northwest due to the combined effect of topography and distant location from the water vapor source. In contrast, higher precipitation was distributed in the southeast, which is located on the verge of mountains and the plain of Sichuan basin [26].
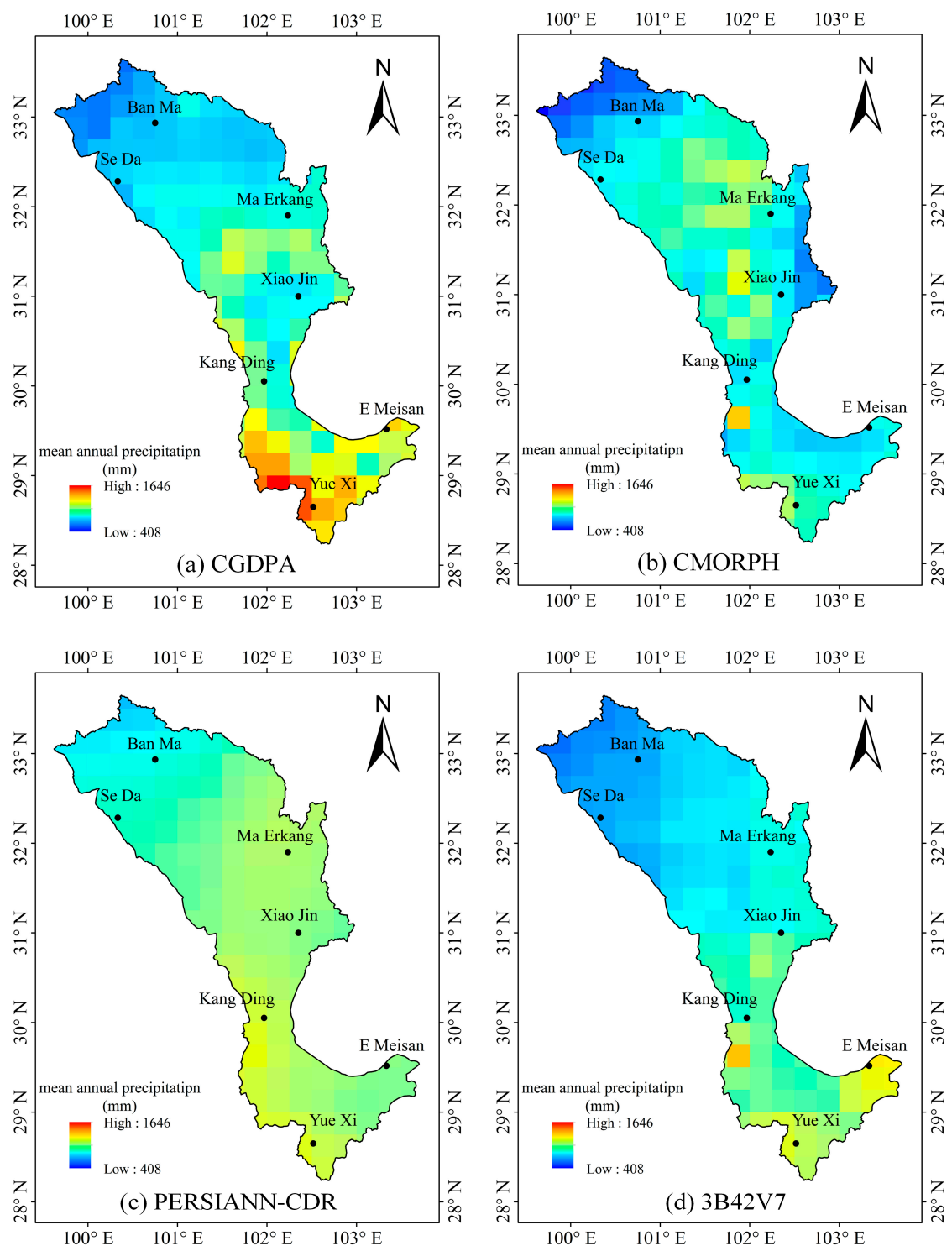

Figure 2. Spatial distribution of mean annual precipitation in the Dadu River basin from 1998 to 2013: (a) China Gauge-Based Daily Precipitation Analysis (CGDPA); (b) MORPHing algorithm (CMORPH); (c) Precipitation Estimation from Remotely Sensed Information using Artificial Neural Networks-Climate Data Record (PERSIANN-CDR); and (d) Tropic Rainfall Measuring Mission (TRMM) Multi-satellite Precipitation Analysis (TMPA) 3B42V7. 
Statistics were computed at the seven pixels with rain gauges over the Dadu River basin, which we believe could be better to reveal the actual performance of satellite precipitation (Table 2). In general, the three satellite products showed acceptable capability in estimating daily precipitation in the Dadu River basin, with CCs of $0.66,0.55$, and 0.70, respectively (Table 2, Figure 3a-c). PERSIANN-CDR showed the largest RMSE $(6.06 \mathrm{~mm})$ and MAE $(2.70 \mathrm{~mm})$, the smallest ME $(0.13 \mathrm{~mm})$ and BIAS $(4.63 \%)$.

Table 2. Summary of statistical metrics for the three satellite precipitation products. The metrics were calculated based on grids with gauges.

\begin{tabular}{ccccccccc}
\hline Products & CC & RMSE $(\mathbf{m m})$ & ME $(\mathbf{m m})$ & MAE $(\mathbf{m m})$ & BIAS $(\mathbf{\%})$ & POD & FAR & CSI \\
\hline CMORPH & $0.66^{* *}$ & 5.13 & -0.38 & 2.27 & -14.08 & 0.78 & 0.47 & 0.46 \\
PERSIANN-CDR & $0.55^{* *}$ & 6.06 & 0.13 & 2.70 & 4.63 & 0.81 & 0.45 & 0.49 \\
3B42V7 & $0.70^{* *}$ & 5.25 & -0.18 & 2.18 & -6.76 & 0.77 & 0.37 & 0.53 \\
\hline
\end{tabular}

** Significant at $p<0.01$.
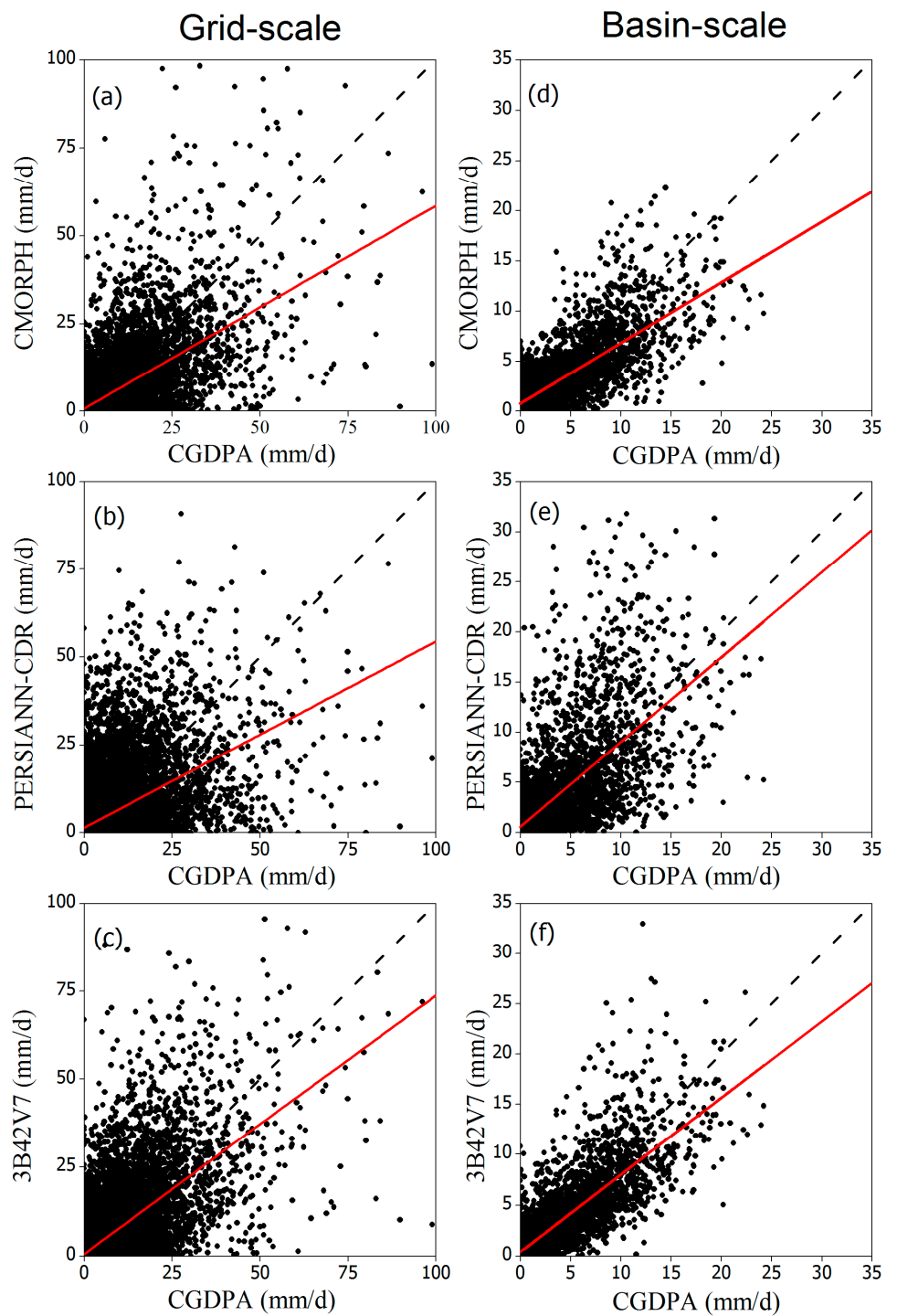

Figure 3. Scatterplots of grid-based precipitation comparison at seven selected grid boxes (first column) and basin-averaged precipitation comparison (second column) in the Dadu River basin: (a,d) for CMORPH, $(\mathbf{b}, \mathbf{e})$ for PERSIANN-CDR, (c,f) for 3B42V7. The diagonal dash line is black, and the best fit line (using the least square method) is red. 
Spatially, The CCs of CMORPH and 3B42V7 performed better skills than that of PERSIANN-CDR (Figure $4 \mathrm{a}-\mathrm{c}$ ). In addition, CMORPH and 3B42V7 showed a similar spatial pattern of CC, with higher values in the downstream and lower values in the upstream. PERSIANN-CDR showed better correlations in the middle area. 3B42V7 had a smaller bias than CMORPH and PERSIANN-CDR across the whole basin. PERSIANN-CDR had relatively larger RMSE over the basin. As for CSI, 3B42V7 performed the best among the three satellite products (Figure $4 \mathrm{j}-1$ ).

The three satellite precipitation products were also compared over the whole basin, with the metrics calculated using basin-averaged precipitation from satellite products and CGDPA. The metrics for whole basin were improved greatly when compared with the grid-scale comparison for all of the products (Figure 3, Table 3), similar with studies in other basins [30]. The CCs of CMORPH and 3B42V7 were 0.78 and 0.83 , respectively, better than that of PERSIANN-CDR with a value of 0.68 (Table 3). The RMSEs were reduced to $2.37 \mathrm{~mm}$ for CMORPH, $3.45 \mathrm{~mm}$ for PERSIANN-CDR and $2.15 \mathrm{~mm}$ for 3B42V7, compared with $5.13 \mathrm{~mm}, 6.06 \mathrm{~mm}$ and $5.25 \mathrm{~mm}$ in the grid-scale comparison. PERSIANN-CDR showed overestimation with positive ME $(0.21 \mathrm{~mm})$ and BIAS $(8.05 \%)$, which was contrary to the underestimation of CMORPH and 3B42V7.

Table 3. Summary of statistical metrics for the three satellite precipitation products. The metrics were calculated based on basin-averaged precipitation.

\begin{tabular}{ccccccccc}
\hline Products & CC & RMSE $(\mathbf{m m})$ & ME $(\mathbf{m m})$ & MAE $(\mathbf{m m})$ & BIAS $\mathbf{( \% )}$ & POD & FAR & CSI \\
\hline CMORPH & $0.78^{* *}$ & 2.37 & -0.27 & 2.30 & -10.67 & 0.93 & 0.29 & 0.67 \\
PERSIANN-CDR & $0.68^{* *}$ & 3.45 & 0.21 & 2.79 & 8.05 & 0.94 & 0.21 & 0.76 \\
3B42V7 & $0.83^{* *}$ & 2.15 & -0.19 & 2.39 & -7.24 & 0.95 & 0.23 & 0.74 \\
\hline \multicolumn{7}{c}{ ** Significant at $p<0.01}$.
\end{tabular}

Annual maximum daily precipitation has great impact on PMP estimation [11]. Figure 5 shows the spatial distribution of the highest and mean values of annual maximum daily precipitation during the 16 years. For both the highest and the mean values of 16-year annual maximum daily precipitation, CMORPH and 3B42V7 performed better than PERSIANN-CDR (Table 4). But, all of the satellite products showed higher values than CGDPA in the upstream (grid number 1-120). We supposed that CGDPA might underestimate the annual maximum daily precipitation since few gauges were installed in the upstream. But, at the same time, CGDPA considered the topographic corrections in the interpolation, and the underestimation should be small.

CMORPH and 3B42V7 showed similar PDFs to that of CGDPA, while PERSIANN-CDR was more centralized around the moderate rainfall than the other three datasets (Figure 6). This was consistent to results in Miao et al. [53]. Moreover, CMORPH and 3B42V7 captured most peaks, especially in the downstream (Figures 5 and 6). PERSIANN-CDR showed a flatter curve with an overestimation in the upstream and an underestimation in the downstream. Because PMP estimation was calculated from the annual maximum daily precipitation, the poor performance of PERSIANN-CDR would influence the PMP estimation.

According to the comprehensive evaluation of the three satellite precipitation estimates at different scales, CMORPH and 3B42V7 performed better in the Dadu River basin, especially in capturing extreme rainfall. All of the satellite products showed an overestimation in the upstream (Figures $4 \mathrm{~d}-\mathrm{f}$ and 5 ). This might be attributed to the performance of satellite rainfall estimation algorithm and sparse gauge networks, as well as complex terrains $[27,54,55]$. Rigid climate in this basin posed a challenge for accurate satellite precipitation estimation [56]. Because satellite precipitation algorithms did well in detecting strong, convective precipitation events, but tend to miss shallow precipitation events [46,57]. In addition, seasonal snow-ice cover over the upstream of the Dadu River basin may be responsible for precipitation overestimation because ice and snow cover can be easily misclassified as rain clouds by Passive Microwave (PMW) [58]. As for the poor performance of PERSIANN-CDR in the Dadu River basin, it was explained by the low quality of IR-based precipitation estimates [59] and the limited gauge information to train the parameters of PERSINN-CDR algorithm [60]. 


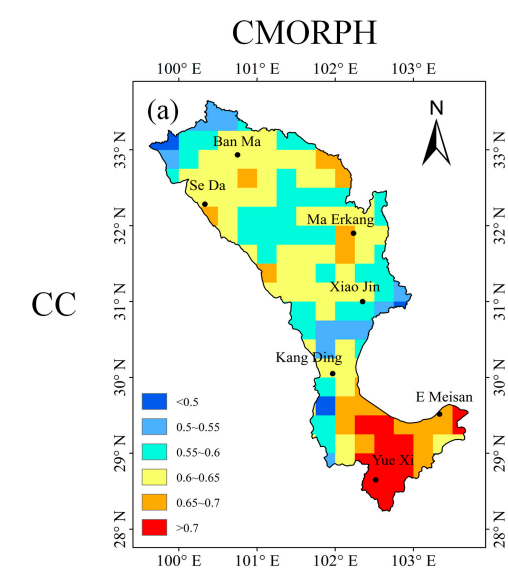

PERSIANN-CDR

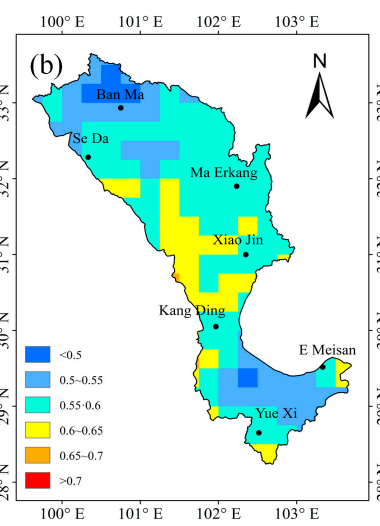

$100^{\circ} \mathrm{E} \quad 101^{\circ} \mathrm{E} \quad 102^{\circ} \mathrm{E} \quad 103^{\circ} \mathrm{E}$

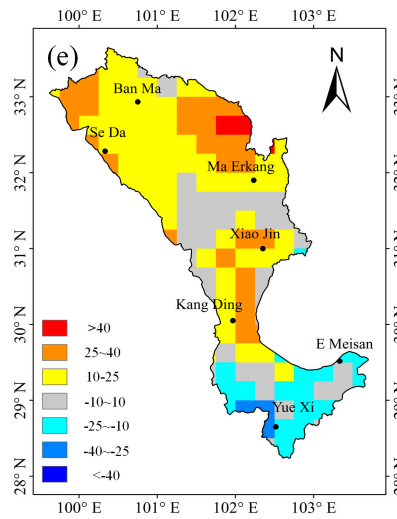

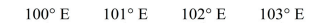
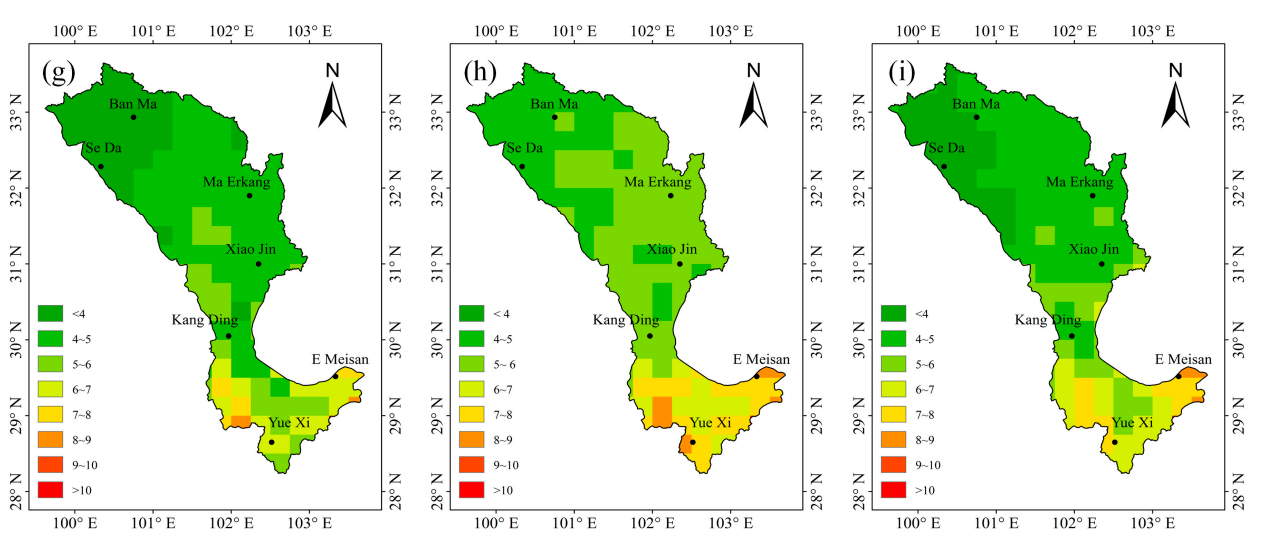

$100^{\circ} \mathrm{E} \quad 101^{\circ} \mathrm{E} \quad 102^{\circ} \mathrm{E} \quad 103^{\circ} \mathrm{E}$

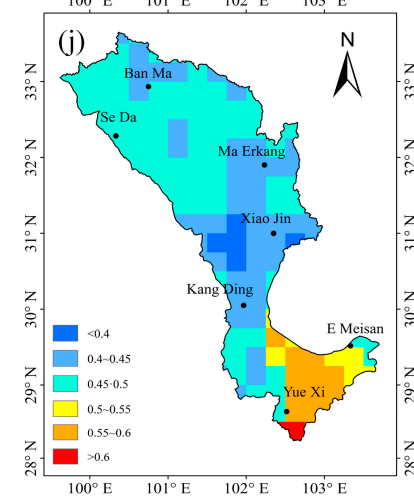

$3 \mathrm{~B} 42 \mathrm{~V} 7$
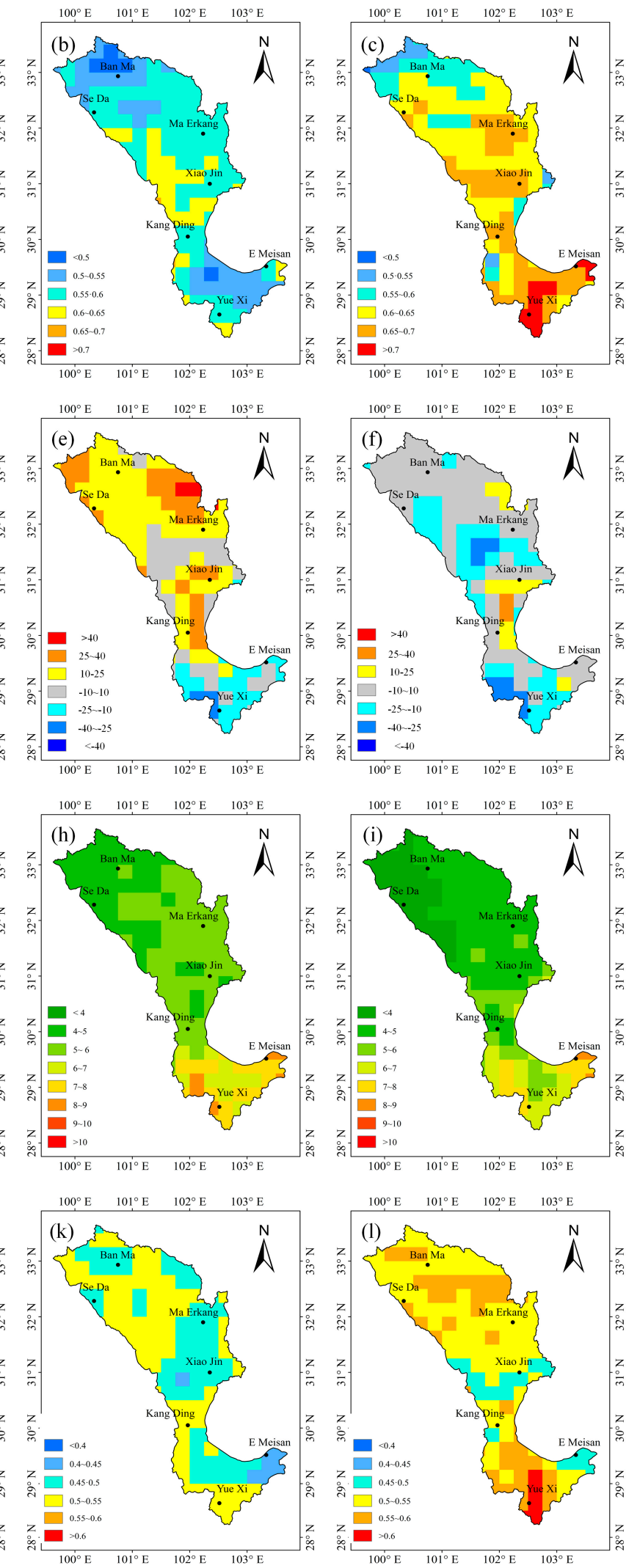

Figure 4. Spatial distributions of statistical metrics for CMORPH (first column), PERSIANN-CDR (second column) and 3B42V7 (third column): (a-c) CC, (d-f) BIAS, (g-i) RMSE and (j-1) CSI. 


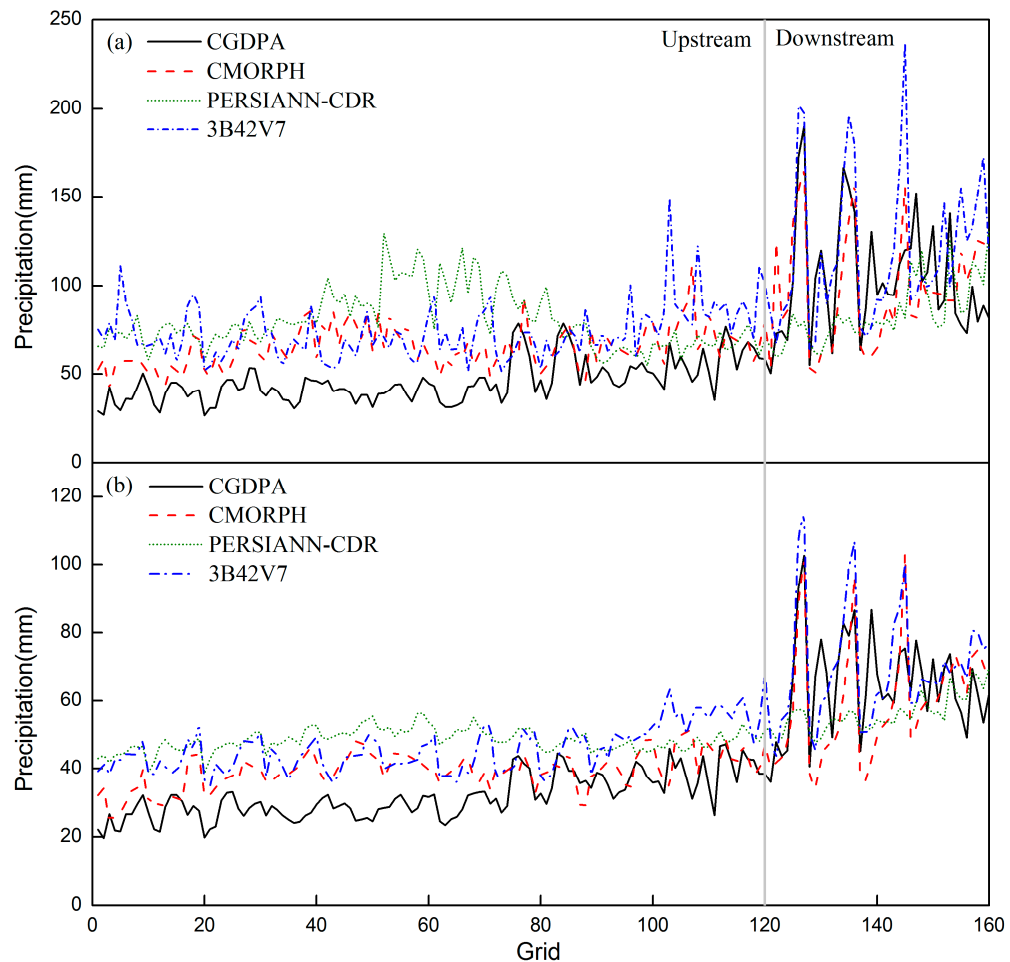

Figure 5. Spatial comparison of (a) the highest values and (b) the mean values of 16-year annual maximum daily precipitation at the whole basin. (Each grid in the basin is numbered with longitude increased from west to east and latitude decreased from north to south, among which grid 1-120 are defined as the upstream, the others as the downstream.).
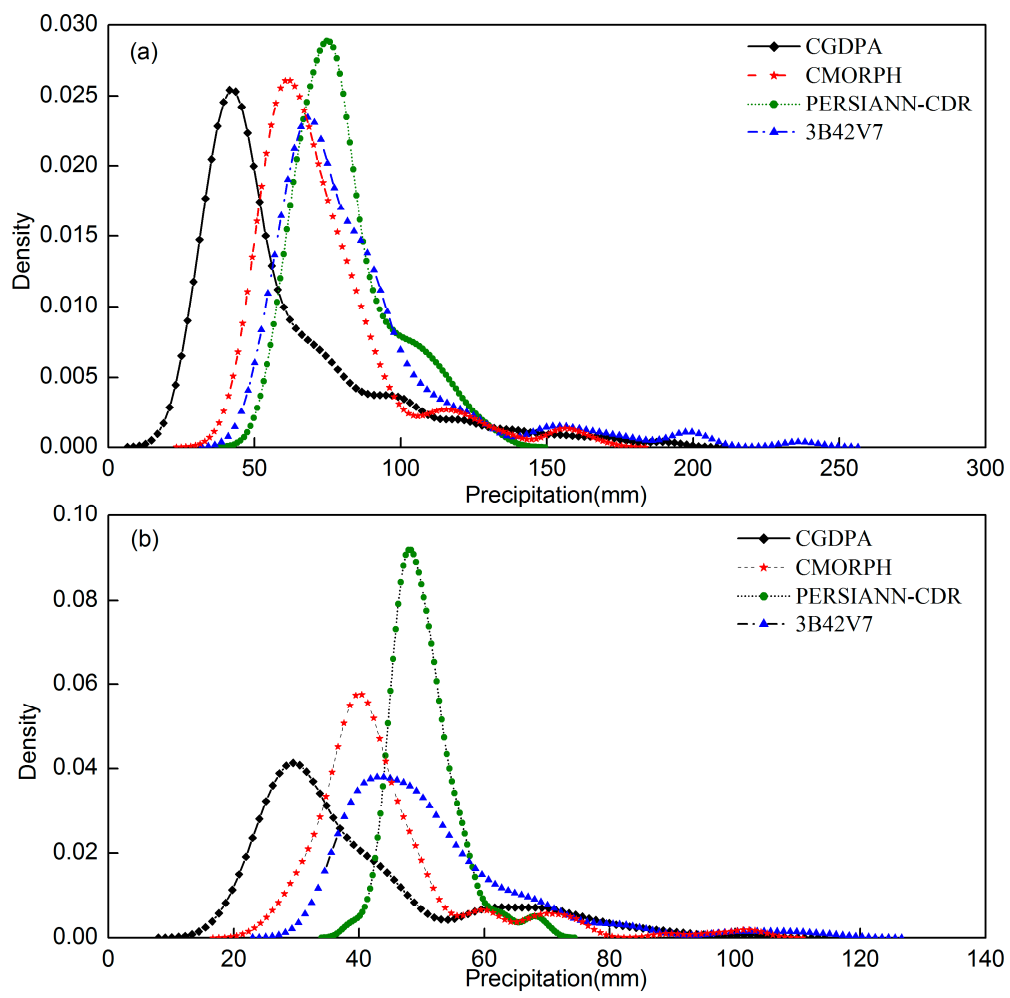

Figure 6. Probability density function (PDF) of (a) the highest and (b) the mean values of 16-year annual maximum daily precipitation in the Dadu River basin. 


\subsection{PMP Estimation and Evaluation}

\subsubsection{4-h PMP Evaluation}

A plot of $K_{m}$ versus the mean 24-h maximum rainfall is given in Figure 7. It is noted that an upper envelope of the statistic, $K_{m}$, had a tendency to decrease with increasing rainfall magnitude. Due to the large uncertainties of drawing the enveloped curve of $K_{m}-\bar{X}_{n}{ }^{\prime}$, we took the largest value of $K_{m}$ over all the grids as the $K_{M}$ that has been used for the whole basin used to estimate PMP. The $K_{M}$ of the four datasets were 6.63, 5.87, 9.20, and 8.52, respectively (Figure 7).
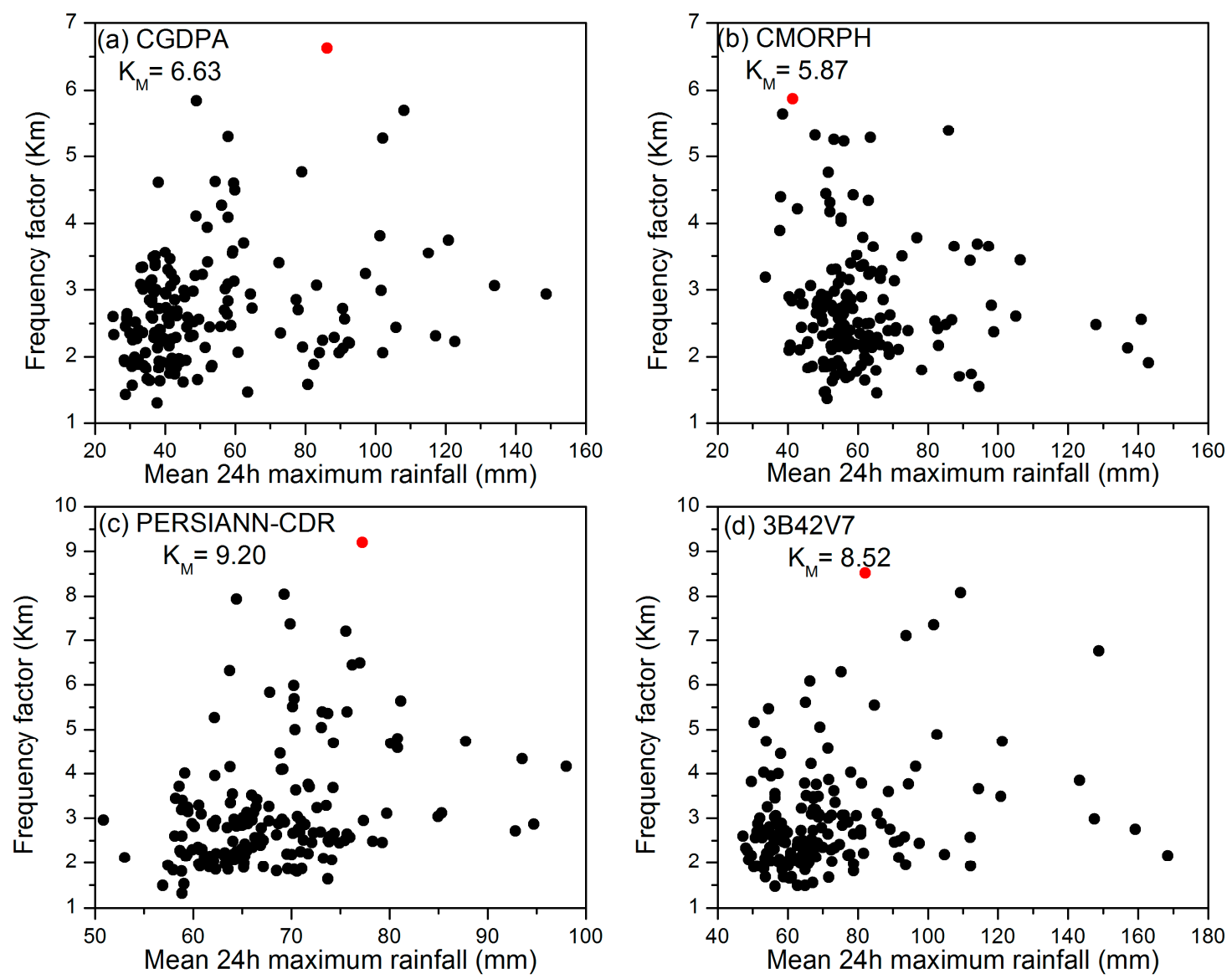

Figure 7. Plot of frequency factor against mean 24-h maximum rainfall (the red dots represent the largest values of $K_{m}$ for the whole basin).

PMP estimates from the three satellite datasets were compared against those of gauge data at the seven grid boxes (Figure 8). CMORPH and 3B42V7 showed larger PMP values than CGDPA, which could be attributed to their higher rain intensity in the Dadu River basin (Figure 6). 3B42V7 showed more significant overestimation than $\mathrm{CMORPH}$, since 3B42V7 presented much larger peaks in annual maximum precipitation series (Figure 6). The spatial trend of CMORPH and 3B42V7 was similar with that of CGDPA. In the upstream, the PMP values were generally smaller. In the downstream, the PMP values were larger and the E Meisan station, which is near the outlet of the Dadu River basin, showed the largest PMP. However, PERSIANN-CDR showed a different spatial pattern when compared to CGDPA, CMORPH, and 3B42V7, with higher PMP in the upstream and lower PMP in the downstream. It might derive from the inverse spatial distribution of PERSIANN-CDR in annual maximum daily precipitation (see Section 5.1).

For the whole basin, the spatial distributions of PMP of 3B42V7 and CMORPH were relatively similar to that of CGDPA (Figure 9). All of the three products showed the largest PMP near the 
outlet of this basin, where rainstorms frequently occur. However, PERSIANN-CDR showed the largest PMP in the middle of upstream. Therefore, CMORPH and 3B42V7 presented good correlations (0.63, 0.70, respectively) with CGDPA, while PERSIANN-CDR showed a big mismatch with CGDPA (Table 4). The PMP values ranged between 51.88-519.11 mm, 90.16-417.61 mm, 122.41-391.79 mm, and 128.37-740.45 mm for CGDPA, CMORPH, PERSIANN-CDR, and 3B42V7, respectively. PERSIANN-CDR had the smallest PMP range because of its centralization in the middle precipitation intensities.

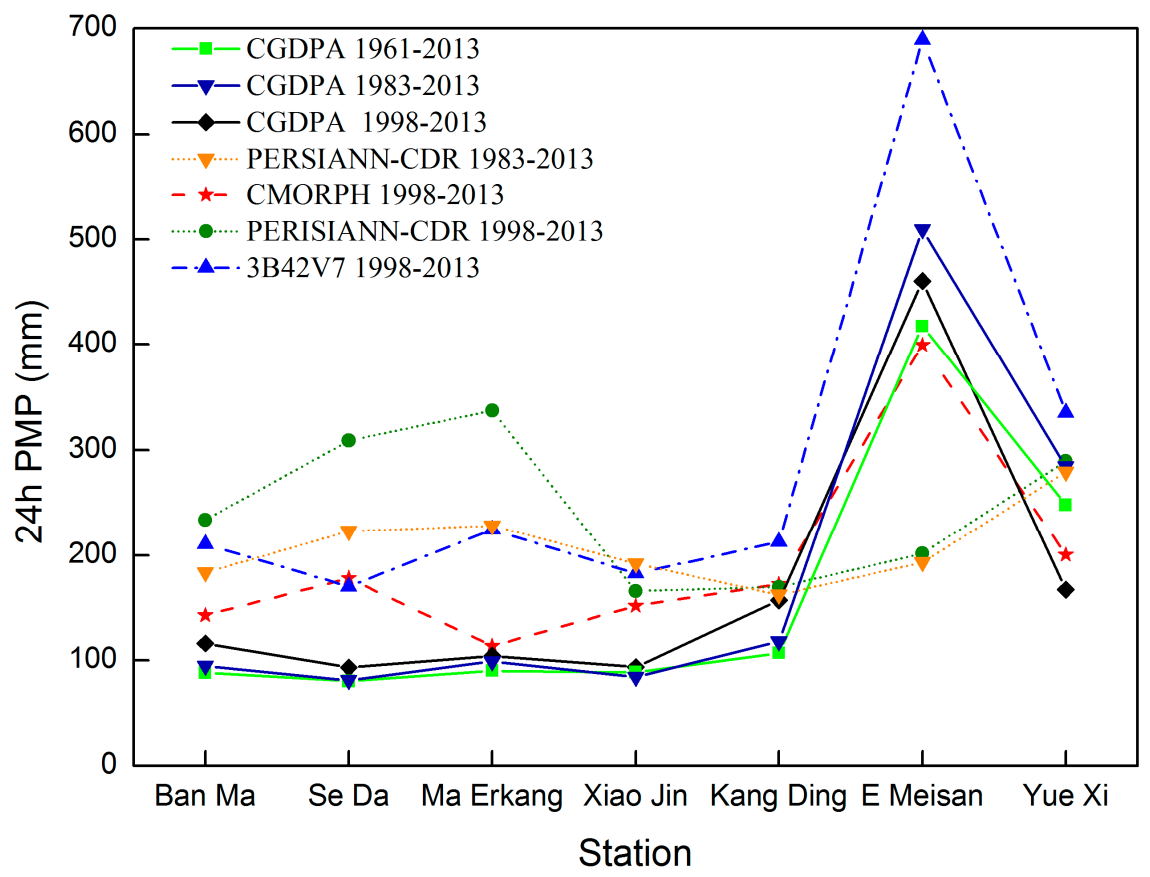

Figure 8. Comparison of 24-h PMP values derived from satellite precipitation and gauge-based precipitation.

Table 4. Summary of spatial Correlation Coefficient (CC) values for the three satellite precipitation products in the Dadu River basin during 1998-2013. The CCs were calculated based on the 160 grids across the basin.

\begin{tabular}{cccc}
\hline & CMORPH & PERSIANN-CDR & 3B42V7 \\
\hline The highest value of annual maximum daily precipitation & $0.68^{* *}$ & 0.08 & $0.71^{* *}$ \\
The mean of annual maximum daily precipitation & $0.76^{* *}$ & $0.62^{* *}$ & $0.83^{* *}$ \\
24-h PMP & $0.63^{* *}$ & -0.08 & $0.70^{* *}$ \\
\hline
\end{tabular}

** Significant at $p<0.01$.

The length of datasets has an important impact on the reliability and robustness of PMP estimation [11]. Thus, CGDPA of 1961-2013, and PERSIANN-CDR of 1983-2013, were used for the further assessment. Similar trends were addressed for the longer dataset from Figures 8 and 9. The PMP estimates based on 53-year, 31-year, and 16-year CGDPA were close to each other, especially in the upstream of the Dadu River basin. Moreover, the PMP estimates based on 31-year and 16-year PERSIANN-CDR exhibited similar spatial pattern, with an overestimation in the upstream and an underestimation in the downstream. The spatial correlations between Figure 9a-g were 0.99, 0.24, 0.95, 0.59, - 0.08, and 0.68, respectively. The performance of CMORPH and 3B42V7 was much better than PERSIANN-CDR, even though PERSIANNN-CDR had a longer data record. When considering the poor performance of PERSIANN-CDR when compared with CGDPA, data quality was critical to PMP estimation. If the quality of satellite precipitation products was improved, the reliability of PMP estimated based on them would also be improved. Due to the rapid development of remote sensing, the future satellite precipitation era will certainly provide more robust and longer datasets for applications, which would make PMP estimation based satellite precipitation become more promising. 


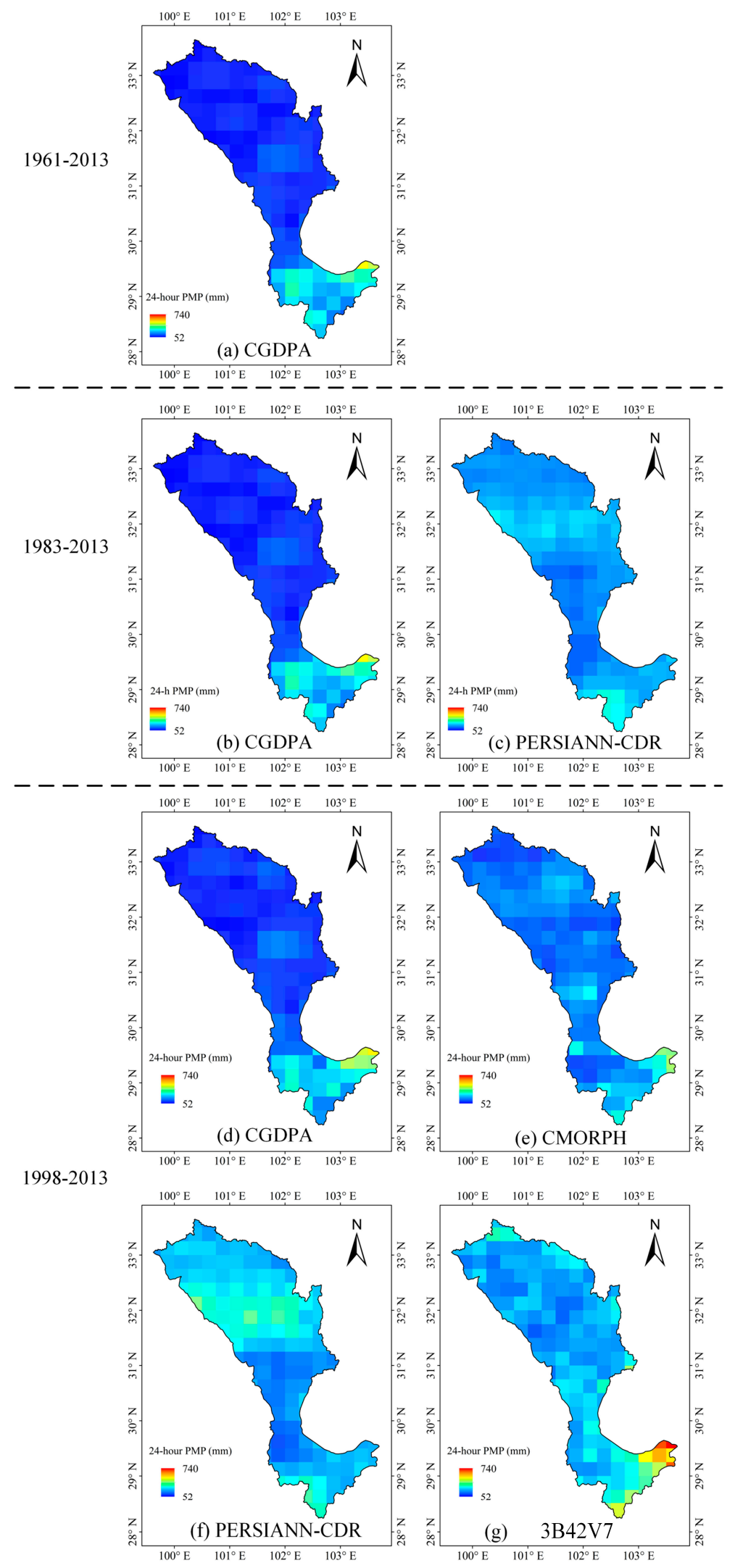

Figure 9. Spatial distribution of 24-h PMP estimation: (a) CGDPA of 1961-2013; (b) CGDPA of 1983-2013; (c) PERSIANN-CDR of 1983-2013; (d) CGDPA of 1998-2013; (e) CMORPH of 1998-2013; (f) PERSIANN-CDR of 1983-2013; and (g) 3B42V7 of 1998-2013. 


\subsubsection{Analysis of the Rationality of PMP Estimates}

The probability and maximality of estimated PMP should be checked before it can be used for engineering design [61]. According to the discussion above, PERSIANN-CDR was not suitable for PMP estimation in the Dadu River basin. Therefore, PERSIANN-CDR was not checked in this section. Here, three methods were used to check the rationality of PMP.

First, the reliability of the PMP estimates can be verified by comparison with results obtained in other PMP-related studies for the same region. The results in this study were compared with the 24-h PMP contour maps in the WMO [11], Wang [61], and Wang [62]. These maps synthesized results obtained from the meteorological method, statistical method and frequency analysis. In the Dadu River basin, the PMP was about $150 \mathrm{~mm}$ in the eastern upstream, 150-200 $\mathrm{mm}$ in the central area, and 600-750 $\mathrm{mm}$ in the eastern downstream, which is the highest in the whole basin (Figure 10). Basically, the spatial distribution in this study agreed well with that in previous literature, showing an increasing trend from upstream to downstream. With regard to the magnitude of PMP values, results of CGDPA, $\mathrm{CMORPH}$, and 3B42V7 in eastern upstream and midstream were comparable to those in the references. However, in the eastern downstream, PMP values based on CGDPA and CMORPH were lower, while values that were based on 3B42V7 were closer to those in published literature. The differences between our results with previous studies could come from the different datasets. The data used in the reference studies have longer time series and possibly include more extreme events. These extreme events could affect variables in Equation (1) and then affect the final PMP values. However, these extreme storms generally happened before the installment of rain gauges and of course, the advent of satellite precipitation, thus can only be obtained through historic documents not from solid data records.
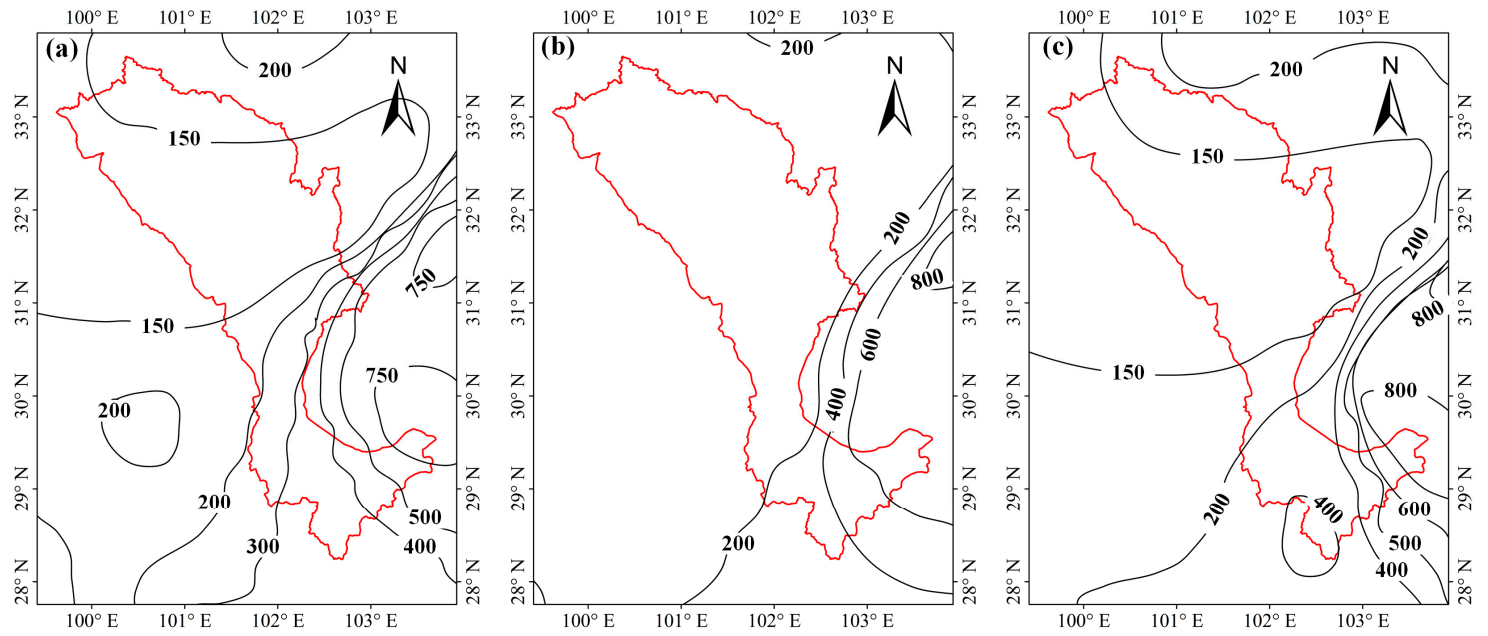

Figure 10. Comparison with historical studies: (a) comparison with WMO (2009); (b) comparison with Wang (1987); and, (c) comparison with Wang (1999).

Secondly, the results were compared with worldwide storm records. The probability of extremely heavy storms occurring in a specific region is small, but from the worldwide perspective, the probability can be much larger. It is assumed that the envelope of maximum precipitation record of different durations approximates the upper physical limit of precipitation. Thus, the estimated PMP values are smaller than this envelope. The empirical equation of worldwide records is $R=422 D^{0.475}(D$ is the storm duration (in $\mathrm{h}$ ), $R$ is total point rainfall accumulation (in $\mathrm{mm}$ )), which indicates that the upper limit of PMP of 24-h duration is about $1900 \mathrm{~mm}$ [11]. PMP estimates in this study were much smaller than the limit. It was reasonable because the geography, terrain, and climate condition should be considered when making comparisons with worldwide storm records [63].

Frequency analysis also provided useful information for PMP values. Gumbel distribution was used in this study for the computation of return periods corresponding to 10, 100 and 1000 years. 
Q-Q plots were used to double check how well theoretical probability distributions fit to the relative frequency histograms. If all of the points in $Q-Q$ plot lie on the line $y=x$, the two distributions match with each other exactly. Gumbel distribution provided a good approximation to the maximum precipitation data for CGDPA, CMORPH, and 3B42V7 (Figure 11). Generalized 24-h rainfall map for 100-year return period is shown in Figure 12. The spatial patterns of CMORPH and 3B42V7 were similar to that of CGDPA, indicating that the two satellite-based products were comparable to the gauge-based product in precipitation corresponding to long return periods. The rainfall values of 10 , 100, and 1000-year return period ranged between $30-229 \mathrm{~mm}, 36-301 \mathrm{~mm}$, and $43-373 \mathrm{~mm}$, respectively. All of them were smaller than the 24-h PMP values because theoretically PMP is so large that the possibility of a rainstorm exceeding PMP is infinitesimally small.
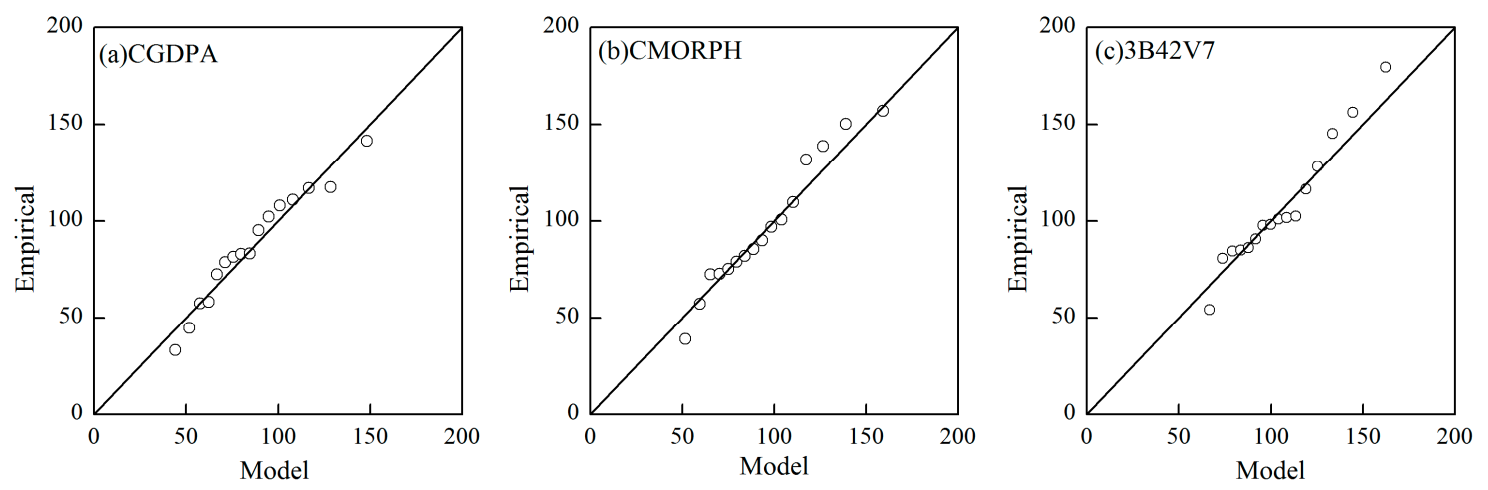

Figure 11. Quantile-Quantile plot for (a) CGDPA; (b) CMORPH; and (c) 3B42V7.
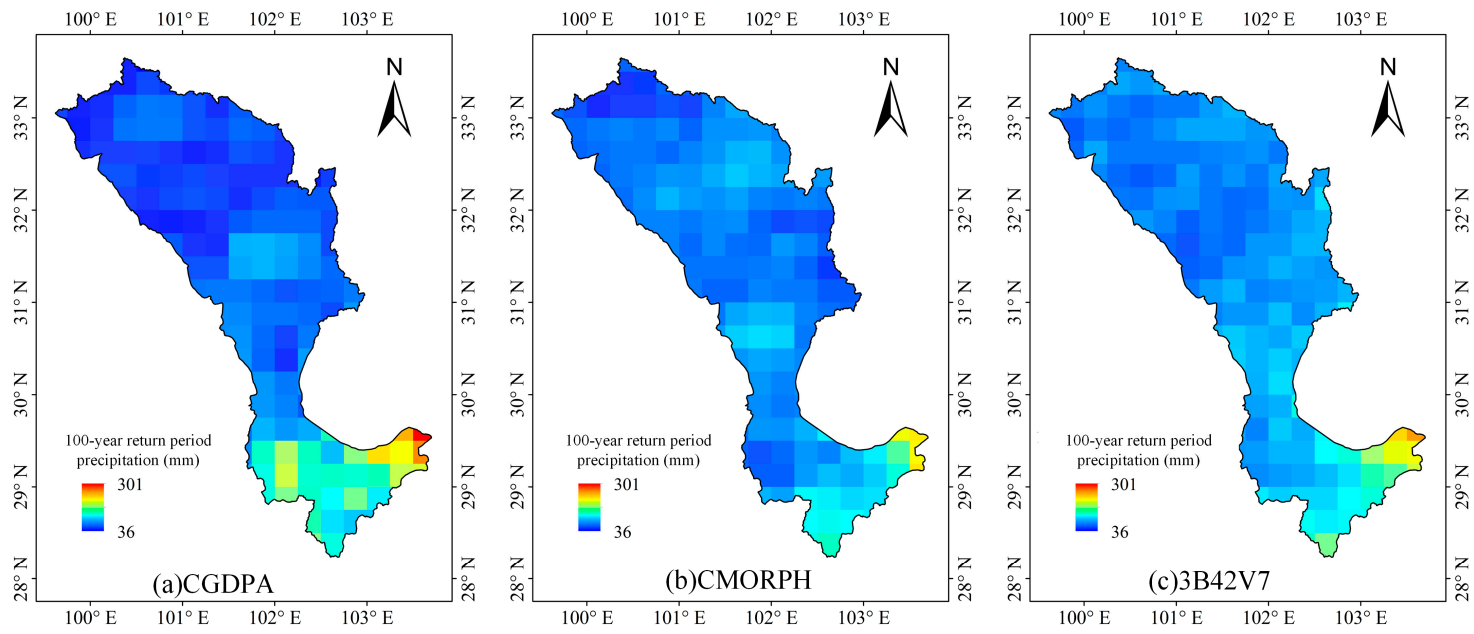

Figure 12. Spatial distribution of 100-year return period precipitation estimation: (a) CGDPA; (b) CMORPH; and (c) 3B42V7.

\section{Discussion}

This study explored the applicability of satellite precipitation data in PMP estimation. However, it should be noted that the quality of the CGDPA as the benchmark dataset could degrade in regions with sparse gauges, especially in mountainous regions. Thus, uncertainties might still exist in the upstream of this basin.

The Hershfield method has been used in many regions over the world [15-23], mostly using gauge datasets. Given the advances of satellite remote sensing technologies, now recent availability of quasi-global satellite precipitation products theoretically enable us to apply the widely used 
Hershfield PMP method solely based on such new dataset in other regions. However, previous studies also revealed that climate and topography variability influence the accuracy of satellite precipitation $[28,34,39,64,65]$. Therefore, it is useful to assess the statistical performance of satellite products, especially for extreme precipitation, before they are applied to estimate PMP in a specific region, which is exactly the goal of the current research. Accordingly, this study suggests that satellite precipitation in other regions, with relative bias within $\pm 15 \%$, CC greater 0.78 , and comparable PDF shape, could be used as alternative data source for PMP estimation.

In hydrology and hydraulic engineering, PMP is primarily used to calculate the PMF that is used in the design of dams. To obtain engineering-design required PMF, higher spatiotemporal resolution PMP is desired. On the other hand, the role of snow melting over the upstream needs to be considered when calculating PMF, particularly over high latitude and high altitude regions. The new generation of GPM (Global Precipitation Mission) could potentially satisfy the above requirements since it provides higher resolution $\left(0.1^{\circ}\right.$ and half-hour) and also precipitation type information (liquid rainfall or solid snowfall) since April 2014. Therefore, in the foreseeable future, higher spatiotemporal resolution PMP should be available and snow melting module could be included in the PMP-PMF model simulation.

\section{Conclusions}

This study initially explored the conventional statistical PMP estimation approach based on satellite precipitation. Three satellite precipitation datasets were used, i.e., CMORPH, PERSIANN-CDR, and 3B42V7. Their performances were firstly assessed against the gauge dataset, i.e., CGDPA, in the Dadu River basin. Comparison and analysis of the PMP estimate from the above datasets were then performed. The primary conclusions were summarized as follows.

1. CMORPH and 3B42V7 agreed well with gauge-based CGDPA for the period of 1998-2013 at both grid and basin scales. PERSIANN-CDR showed an overestimation in the upstream and an underestimation in the downstream. Moreover, CMORPH and 3B42V7 performed better scores than PERSIANN-CDR in term of capturing the extreme precipitation events, with high CCs $(0.68$ and 0.71 , respectively).

2. CMORPH and 3B42V7, the datasets that have better agreements with gauge observations, showed the satisfying performance in PMP estimation and better skills than PERSIANN-CDR in capturing the magnitude and spatial distribution of 24-h PMP. Further analysis of the rationality of PMP estimates also verified the feasibility of PMP results that were derived from CMORPH and 3B42V7 were proper in the Dadu River basin.

In conclusion, CMORPH and 3B42V7 can capture precipitation and can be well applied in PMP estimation. Satellite precipitation can provide valuable data in sparsely gauged or ungauged basins, which is a big advantage over in-situ gauge-based PMP estimation. Therefore, satellite precipitation products have great potential in PMP estimation and planning for hydraulic engineering design.

Acknowledgments: This study was supported by National 973 Project (Grant No. 2013CB036406) and the National Natural Science Foundation of China (Grant No. 71461010701 and 91437214). The authors' great gratitude is extended to the China Meteorological Administration for providing ground-based precipitation data. Efforts of the CMORPH, PERSIANN-CDR and TRMM research community are also highly appreciated for making the data available for international users. Authors thank Yingzhao Ma from Tsinghua University for improving the manuscript. We are also very grateful to the editors and five anonymous reviewers for their critical comments and thoughtful suggestions.

Author Contributions: Y.Y. analyzed the data and prepared the draft of the manuscript. G.T. prepared the satellite precipitation data and revised the manuscript. Both X.L. and N.Y. gave comments. Y.H. conceived of this study, gave comments and revised the manuscript.

Conflicts of Interest: The authors declare no conflict of interest. 


\section{References}

1. Biswas, A.K.; Tortajada, C. Development and large dams: A global perspective. Int. J. Water Resour. Dev. 2001, 17, 9-21. [CrossRef]

2. Hossain, F.; Jeyachandran, I.; Pielke, R. Dam safety effects due to human alteration of extreme precipitation. Water Resour. Res. 2010, 46. [CrossRef]

3. Woldemichael, A.T.; Hossain, F.; Pielke, R.; Beltrán-Przekurat, A. Understanding the impact of dam-triggered land use/land cover change on the modification of extreme precipitation. Water Resour. Res. 2012, 48. [CrossRef]

4. Yigzaw, W.; Hossain, F.; Kalyanapu, A. Impact of artificial reservoir size and land use/land cover patterns on probable maximum precipitation and flood: Case of folsom dam on the american river. J. Hydrol. Eng. 2012, 18, 1180-1190. [CrossRef]

5. Chen, L.C.; Bradley, A.A. Adequacy of using surface humidity to estimate atmospheric moisture availability for probable maximum precipitation. Water Resour. Res. 2006, 42. [CrossRef]

6. Beauchamp, J.; Leconte, R.; Trudel, M.; Brissette, F. Estimation of the summer-fall PMP and PMF of a northern watershed under a changed climate. Water Resour. Res. 2013, 49, 3852-3862. [CrossRef]

7. Collier, C.; Hardaker, P. Estimating probable maximum precipitation using a storm model approach. J. Hydrol. 1996, 183, 277-306. [CrossRef]

8. Rakhecha, P.; Clark, C. Revised estimates of one-day probable maximum precipitation (PMP) for India. Meteorol. Appl. 1999, 6, 343-350. [CrossRef]

9. Rezacova, D.; Pesice, P.; Sokol, Z. An estimation of the probable maximum precipitation for river basins in the Czech Republic. Atmos. Res. 2005, 77, 407-421. [CrossRef]

10. Svensson, C.; Rakhecha, P. Estimation of probable maximum precipitation for dams in the Hongru river catchment, China. Theor. Appl. Climatol. 1998, 59, 79-91. [CrossRef]

11. World Meteorological Organization (WMO). Manual on Estimation of Probable Maximum Precipitation (PMP), 3rd ed.; World Meteorological Organization (WMO): Geneva, Switzerland, 2009; ISBN 978-92-63-11045-9.

12. Rakhecha, P.; Soman, M. Estimation of probable maximum precipitation for a 2-day duration: Part 2-North Indian region. Theor. Appl. Climatol. 1994, 49,77-84. [CrossRef]

13. Hershfield, D.M. Estimating the probable maximum precipitation. J. Hydraul. Eng. Div. ASCE 1961, 87, 99-116.

14. Hershfield, D.M. Method for estimating probable maximum rainfall. J. Am. Water Works Assoc. 1965, 57, 965-972.

15. Chavan, S.R.; Srinivas, V. Probable maximum precipitation estimation for catchments in Mahanadi river basin. Aquat. Procedia 2015, 4, 892-899. [CrossRef]

16. Deshpande, N.; Kulkarni, B.; Verma, A.; Mandal, B. Extreme rainfall analysis and estimation of probable maximum precipitation (PMP) by statistical methods over the Indus river basin in India. J. Spat. Hydrol. 2008, 8, 22-35.

17. Casas, M.C.; Rodríguez, R.; Nieto, R.; Redaño, A. The estimation of probable maximum precipitation. Ann. N. Y. Acad. Sci. 2008, 1146, 291-302. [CrossRef] [PubMed]

18. Casas, M.C.; Rodríguez, R.; Prohom, M.; Gázquez, A.; Redaño, A. Estimation of the probable maximum precipitation in Barcelona (Spain). Int. J. Climatol. 2011, 31, 1322-1327. [CrossRef]

19. Fattahi, E.; Noorian, A.; Noohi, K. Comparison of physical and statistical methods for estimating probable maximum precipitation in southwestern basins of Iran. Desert 2011, 15, 127-132.

20. Shirdeli, A. Probable maximum precipitation 24 h estimation: A case study of Zanjan province of Iran. Manag. Sci. Lett. 2012, 2, 2237-2242. [CrossRef]

21. Alias, N.E.; Luo, P.; Takara, K. Probable maximum precipitation using statistical method for the Yodo river basin. J. Jpn. Soc. Civ. Eng. Ser. B1 (Hydraul. Eng.) 2013, 69, I_157-I_162. [CrossRef]

22. Desa, M.M.N.; Noriah, A.B.; Rakhecha, P.R. Probable maximum precipitation for $24 \mathrm{~h}$ duration over southeast Asian Monsoon region-Selangor, malaysia. Atmos. Res. 2001, 58, 41-54. [CrossRef]

23. Desa, M.M.N.; Rakhecha, P.R. Probable maximum precipitation for 24 -h duration over an equatorial region: Part 2-Johor, Malaysia. Atmos. Res. 2007, 84, 84-90. [CrossRef]

24. Rakhecha, P.; Singh, V.P. Applied Hydrometeorology; Springer Science \& Business Media: Dordrecht, The Netherlands, 2009; ISBN 978-1-4020-9844-4. 
25. Wu, Y.; Wang, W.; Wang, G. Detecting variation trends of temperature and precipitation for the Dadu river basin, China. Adv. Meteorol. 2016, 2016. [CrossRef]

26. Tu, Y. Significance of the Power Generation of Dagangshan Hydropower Station on the Development of Dadu River basin. Water Power 2015, 41, 1-4. (In Chinese)

27. Shen, Y.; Xiong, A. Validation and comparison of a new gauge-based precipitation analysis over mainland China. Int. J. Climatol. 2016, 36, 252-265. [CrossRef]

28. Xie, P.; Chen, M.; Yang, S.; Yatagai, A.; Hayasaka, T.; Fukushima, Y.; Liu, C. A gauge-based analysis of daily precipitation over East Asia. J. Hydrometeorol. 2007, 8, 607-626. [CrossRef]

29. Tang, G.; Zeng, Z.; Long, D.; Guo, X.; Yong, B.; Zhang, W.; Hong, Y. Statistical and hydrological comparisons between trmm and gpm level-3 products over a midlatitude basin: Is day-1 imerg a good successor for TMPA 3b42v7? J. Hydrometeorol. 2016, 17, 121-137. [CrossRef]

30. Tang, G.; Ma, Y.; Long, D.; Zhong, L.; Hong, Y. Evaluation of gpm day-1 imerg and TMPA version-7 legacy products over mainland China at multiple spatiotemporal scales. J. Hydrol. 2016, 533, 152-167. [CrossRef]

31. Sun, R.; Yuan, H.; Liu, X.; Jiang, X. Evaluation of the latest satellite-gauge precipitation products and their hydrologic applications over the Huaihe River basin. J. Hydrol. 2016, 536, 302-319. [CrossRef]

32. Guo, H.; Chen, S.; Bao, A.; Behrangi, A.; Hong, Y.; Ndayisaba, F.; Hu, J.; Stepanian, P. Early assessment of Integrated Multi-satellite Retrievals for Global Precipitation Measurement over China. Atmos. Res. 2016, 176, 121-133. [CrossRef]

33. Chen, X.; Long, D.; Hong, Y.; Zeng, C.; Yan, D. Improved modeling of snow and glacier melting by a progressive two-stage calibration strategy with GRACE and multisource data: How snow and glacier meltwater contributes to the runoff of the Upeer Brahmaputra River basin? Water Resour. Res. 2017, 53, 2431-2466. [CrossRef]

34. Chen, S.; Hong, Y.; Cao, Q.; Gourley, J.J.; Kirstetter, P.E.; Yong, B.; Tian, Y.; Zhang, Z.; Shen, Y.; Hu, J.; et al. Similarity and difference of the two successive v6 and v7 TRMM multisatellite precipitation analysis performance over China. J. Geophys. Res. Atmos. 2013, 118, 13060-13074. [CrossRef]

35. Gao, Z.; Long, D.; Tang, G.; Zeng, C.; Huang, J.; Hong, Y. Assessing the potential of satellite-based precipitation estimates for flood frequency analysis in ungauged or poorly gauged tributaries of China's Yangtze river basin. J. Hydrol. 2017, 550, 478-496. [CrossRef]

36. Ning, S.; Song, F.; Udmale, P.; Jin, J.; Thapa, B.R.; Ishidaira, H. Error analysis and evaluation of the latest gsmap and imerg precipitation products over eastern China. Adv. Meteorol. 2017, 11, 1-16. [CrossRef]

37. Yong, B.; Wang, J.; Ren, L.; You, Y.; Xie, P.; Hong, Y. Evaluating four multi-satellite precipitation estimates over Diaoyu islands during typhoon seasons. J. Hydrometeorol. 2017, 17, 1623-1641. [CrossRef]

38. Zhang, C.; Tang, Q.; Chen, D.; Li, L.; Liu, X.; Cui, H. Tracing changes in atmospheric moisture supply to the drying southwest China. Atmos. Chem. Phys. 2017, 17, 1-19. [CrossRef]

39. Yong, B.; Chen, B.; Tian, Y.; Yu, Z.; Hong, Y. Error-component analysis of TRMM-based multi-satellite precipitation estimates over mainland China. Remote Sens. 2017, 8, 440. [CrossRef]

40. Joyce, R.J.; Janowiak, J.E.; Arkin, P.A.; Xie, P. Cmorph: A method that produces global precipitation estimates from passive microwave and infrared data at high spatial and temporal resolution. J. Hydrometeorol. 2004, 5, 487-503. [CrossRef]

41. Ashouri, H.; Hsu, K.-L.; Sorooshian, S.; Braithwaite, D.K.; Knapp, K.R.; Cecil, L.D.; Nelson, B.R.; Prat, O.P. Persiann-cdr: Daily precipitation climate data record from multisatellite observations for hydrological and climate studies. Bull. Am. Meteorol. Soc. 2015, 96, 69-83. [CrossRef]

42. Huffman, G.J.; Bolvin, D.T.; Nelkin, E.J.; Wolff, D.B.; Adler, R.F.; Gu, G.; Hong, Y.; Bowman, K.P.; Stocker, E.F. The TRMM multisatellite precipitation analysis (TMPA): Quasi-global, multiyear, combined-sensor precipitation estimates at fine scales. J. Hydrometeorol. 2007, 8, 38-55. [CrossRef]

43. Shen, Y.; Pan, Y.; Yu, J.; Zhao, P.; Zhou, Z. Quality assessment of hourly merged precipitation product over China. Trans. Atmos. Sci. 2013, 36, 37-46. (In Chinese)

44. Chow, V.T. A general formula for hydrologic frequency analysis. EOS Trans. AGU 1951, 32, 231-237. [CrossRef]

45. Lin, B.; Vogel, J. A new look at the statistical estimation of PMP. In Proceedings of the Symposium, Engineering Hydrology, ASCE, San Francisco, CA, USA, 25-30 July 1993; pp. 629-634.

46. Klein Tank, A.M.G.; Zwiers, F.W.; Zhang, X. Guidelines on Analysis of Extremes in a Changing Climate in Support of Informed Decisions for Adaptation; World Meteorological Organization: Geneva, Switzerland, 2009. 
47. Burke, E.J.; Perry, R.H.; Brown, S.J. An extreme value analysis of uk drought and projections of change in the future. J. Hydrol. 2010, 388, 131-143. [CrossRef]

48. Oosterbaan, R.J.; Ritzema, H. Frequency and regression analysis. In Drainage Principles and Applications, 2nd ed.; Ritzema, H.P., Ed.; International Institute for Land Reclamation and Improvement (ILRI): Wageningen, The Netherlands, 1994; pp. 175-223.

49. Hershfield, D.M.; Kohler, M.A. An empirical appraisal of the gumbel extreme-value procedure. J. Geophys. Res. Atmos. 1960, 65, 1737-1746. [CrossRef]

50. Leese, M.N. Use of censored data in the estimation of gumbel distribution parameters for annual maximum flood series. Water Resour. Res. 1973, 9, 1534-1542. [CrossRef]

51. Ebert, E.E.; Janowiak, J.E.; Kidd, C. Comparison of near-real-time precipitation estimates from satellite observations and numerical models. Bull. Am. Meteorol. Soc. 2007, 88, 47. [CrossRef]

52. Yong, B.; Ren, L.L.; Hong, Y.; Wang, J.H.; Gourley, J.J.; Jiang, S.H.; Chen, X.; Wang, W. Hydrologic evaluation of multisatellite precipitation analysis standard precipitation products in basins beyond its inclined latitude band: A case study in laohahe basin, china. Water Resour. Res. 2010, 46. [CrossRef]

53. Miao, C.; Ashouri, H.; Hsu, K.-L.; Sorooshian, S.; Duan, Q. Evaluation of the persiann-cdr daily rainfall estimates in capturing the behavior of extreme precipitation events over china. J. Hydrometeorol. 2015, 16, 1387-1396. [CrossRef]

54. Guo, H.; Chen, S.; Bao, A.; Hu, J.; Yang, B.; Stepanian, P.M. Comprehensive evaluation of high-resolution satellite-based precipitation products over china. Atmosphere 2016, 7, 6. [CrossRef]

55. Yang, Y.; Luo, Y. Evaluating the performance of remote sensing precipitation products cmorph, persiann, and tmpa, in the arid region of northwest china. Theor. Appl. Climatol. 2014, 118, 429-445. [CrossRef]

56. Dinku, T.; Ceccato, P.; Grover-Kopec, E.; Lemma, M.; Connor, S.J.; Ropelewski, C.F. Validation of satellite rainfall products over east Africa's complex topography. Int. J. Remote Sens. 2007, 28, 1503-1526. [CrossRef]

57. Chen, S.; Hong, Y.; Cao, Q.; Tian, Y.; Hu, J.; Zhang, X.; Li, W.; Carr, N.; Shen, X.; Qiao, L. Intercomparison of precipitation estimates from wsr-88d radar and trmm measurement over continental united states. IEEE Trans. Geosci. Remote 2015, 53, 4444-4456. [CrossRef]

58. Hirpa, F.A.; Gebremichael, M.; Hopson, T. Evaluation of high-resolution satellite precipitation products over very complex terrain in ethiopia. J. Appl. Meteorol. Clim. 2010, 49, 1044-1051. [CrossRef]

59. Guo, H.; Chen, S.; Bao, A.; Hu, J.; Gebregiorgis, A.S.; Xue, X.; Zhang, X. Inter-comparison of high-resolution satellite precipitation products over central asia. Remote Sens. 2015, 7, 7181-7211. [CrossRef]

60. Li, Z.; Yang, D.; Hong, Y. Multi-scale evaluation of high-resolution multi-sensor blended global precipitation products over the yangtze river. J. Hydrol. 2013, 500, 157-169. [CrossRef]

61. Wang, G. Principles and Methods of PMP/PMF Calculations; China Hydrology and Hydroelectric Press and Yellow River Water Resources Publishing House: Beijing, China; Zhenzhou, China, 1999; ISBN 978-7-80621-323-0. (In Chinese)

62. Wang, J. Study of design storms in China. J. Hydrol. 1987, 96, 279-291. [CrossRef]

63. Wang, G.; Li, B.; Wang, J. World's greatest known point rainfalls and their enveloping curve formula. Adv. Water Sci. 2006, 17, 824.

64. Shen, Y.; Xiong, A.Y.; Wang, Y.; Xie, P.P. Performance of high-resolution satellite precipitation products over China. J. Geophys. Res. Atmos. 2010, 115. [CrossRef]

65. Gebregiorgis, A.S.; Tian, Y.; Peters-Lidard, C.D.; Hossain, F. Tracing hydrologic model simulation error as a function of satellite rainfall estimation bias components and land use and land cover conditions. Water Resour. Res. 2012, 48. [CrossRef]

(C) 2017 by the authors. Licensee MDPI, Basel, Switzerland. This article is an open access article distributed under the terms and conditions of the Creative Commons Attribution (CC BY) license (http://creativecommons.org/licenses/by/4.0/). 